\title{
Pre-Pregnancy Obesity: A friend or foe for Vitamin D
}

\author{
Fareeha Shahid, Farhan Muhammad Qureshi
}

\section{INTRODUCTION:}

Vitamin D and its active metabolite 1,25 - dihydrooxyvitamin $\mathrm{D}(1,25(\mathrm{OH}) 2 \mathrm{D})$ has been generally recognized as repertoire of many classical (calcium balance and bone metabolism) and non-classical effects (non-calcium actions) such as promotion of insulin secretion and its action, immunomodulation. Absorption of calcium and phosphorus depends on sufficient vitamin D levels. Its low level leads to demineralization of bone both in children and adults. Vitamin D has also a significant role and has potential to influence many factors in the developing fetus. Newborns are at high risk of developing hypocalcaemic tetany as a consequence of maternal deficiency of vitamin D.

\section{Pregnancy, Obesity and Vitamin D:}

Insufficiency of Vitamin D is an emerging public health concern across the globe especially among the women during their reproductive phases of life. Obesity in the reproductive phase of women's life is another notable risk factor for vitamin D insufficiency that increases the risk of maternal and fetal complications. ${ }^{1}$ The time after conceiving is crucial for women as they are more susceptible to vitamin D deficiency, as they sustain their own vitamin D reservoirs along with their babies. ${ }^{2}$ Moreover, More than 14 million women suffer from maternal complication every year, especially in developing countries. ${ }^{3}$

Maternal vitamin D levels directly linked to the fetal vitamin D levels and its insufficient level is a major cause of low gestational fetal weight, neonatal hypocalcaemia, reduced weight and size infant and juvenile rickets. ${ }^{4,5}$ Prepregnancy obesity related adverse outcomes such as miscarriage, preeclampsia and gestational diabetes and its associated fetal overgrowth are mediated by the deficiency of active metabolite of vitamin D which has a significant role in the development and function of placenta, inflammation, angiogenesis, immunomodulation and insulin sensitivity. ${ }^{2}$ The development and right progression of fetus and placenta depends on vitamin $D$ receptors and an activating enzyme (1-a-hydroxylase) in placenta which acts as a modulators.

- - - - - - - - - - - - - - - -

I Fareeha Shahid

Assistant Professor

Department of Community Health Sciences

Bahria University Medical \& Dental College

I Email: drfareeha@live.com

Farhan Muhammad Qureshi

Assistant Professor,

I Department of Community Health Sciences

I Karachi Institute of Medical Sciences

I Received: 16-12-2019

I Accepted: 22-12-2019

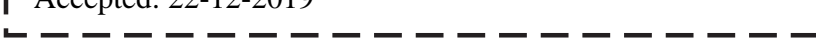

They also plays a significant role in maternal as well as fetal blood glucose regulation. ${ }^{6}$ The excess of adipose tissue in overweight and obese individuals causes sequestering of active form of vitamin $\mathrm{D}$ and stored it, in an inactive form in the body. ${ }^{7}$ Thus and so, it has been noticed among pregnant women whose body mass index $(\mathrm{BMI})>30$ are at major risk of vitamin D insufficiency due to decrease insulin sensitivity. ${ }^{8,9}$ Studies suggest that healthy, non-obese individuals had higher levels of circulating active metabolite of vitamin D as compare to the obese individuals. ${ }^{10}$ Dark skin individuals and inadequate exposure to sunlight due to any reason is associated with reduction in the synthesis of cholecalciferol $\left(\mathrm{D}_{3}\right)$ in skin through UV radiation from sunlight that is considered to be the significant source of vitamin D. ${ }^{11}$ It might be the reason of vitamin D deficiency among obese individuals including obese pregnant women as they spend most of their time at home and not exposing themselves to sun. ${ }^{12}$ Hence, pregnant woman who is vitamin deficient both due to sunlight exposure and due to insulin sensitivity must concerned their own health as well as their babies. Obese and women with dark pigmented skin or covered skin need to be careful regarding their vitamin D levels and consult to the health practitioner to rule out the cause and treatment if required.

\section{Public Health Concern:}

Being the public health issue, pregnancy related metabolic disorders and deregulations becoming challenge not only for the mother and its baby but also influence and burdened the entire family. Efficient and effective strategic interventions such as public awareness and professional educational programs at mass level regarding benefits of sun exposure at prescribed phase, physical activities, healthy and nutritional diet work as a helping hand and ultimately reduce the overall economic, social, emotional and health related burden. ${ }^{13}$ In addition, family counselling also play a vital role to deal with the lethal scenario and to prevent the prenatal, intranatal and post natal life threatening conditions in mothers and adverse health consequences in the newborns. ${ }^{14}$ Despite the recommendation in many documents of National Health Service guidance regarding the prevention and management of Prepregnancy condition such as obesity and diabetes but, unfortunately, there is limited provision so far for such service. Health promotion techniques helps to gain insight to improve general health and able to persuade them to adopt healthy lifestyle. Further, weight loss guidance prior to conceive the child would help to control the pregnancy related problems and able to cope the possible complications. Screening for the vitamin D status in child bearing age especially among the obese women who are planning to 
conceive may benefit by giving high dose supplementation to improve their vitamin D reservoirs as well as their babies. ${ }^{15}$

\section{Recommendations to combat vitamin D deficiency:}

Despite a dearth evidence that supports the vitamin D supplementation and treatment in clinical trial settings, it is widely accepted that regular intake of vitamin D supplements and treatment of its deficiency is safe and recommended for all women especially the pregnant and lactating mothers. However, consultation with doctor is necessary for the optimal dose of vitamin D use to achieve potential health benefits in short and long term. All pregnant and breastfeeding women should also be encouraged to receive adequate, healthy and nutritious food. Fortification of food with vitamin D may improve the deficiency and overall health status, not only in women but also in children. World Health Organization (WHO) recommended vitamin D supplementation in pregnant women in its 2012 guidelines. Sunlight is the most important source of vitamin D, hence sunlight exposure at a prescribed phase is necessary for pregnant women as well as general population. However, the time and amount of sunlight exposure is not known and rely on many factors such as time of the day, amount of skin exposed, latitude and season, skin pigmentation (lighter skin pigments synthesize more vitamin $\mathrm{D}$ as compare to darker pigments) and use of sun shades and screens.

\section{CONCLUSION:}

Obesity especially prepregnancy obesity has been identified among multiple factors involve in vitamin D deficiency among women especially pregnant women. Steps must be taken to identify and treat the condition both in clinical and public health setting in order to combat the complication arise in mother, fetus and in newborn. The emerging cases of obesity before and during pregnancy rises the maternal, fetal and newborn vitamin D deficiency related complication will threat to become a serious public health issue, if not planned and managed efficiently and effectively.

\section{REFERENCES:}

1. Al-Musharaf S, Fouda M, Turkestani I, Al-Ajlan A, Sabico S, Alnaami A, Wani K, Hussain S, Alraqebah B, Al-Serehi A, Alshingetti N. Vitamin D deficiency prevalence and predictors in early pregnancy among Arab women. Nutrients. 2018;10(4):489.
2. Bodnar LM, Catov JM, Roberts JM, Simhan HN. Prepregnancy obesity predicts poor vitamin D status in mothers and their neonates. The Journal of nutrition. 2007;137(11):2437-42.

3. Hogan MC, Foreman KJ, Naghavi M. Maternal mortality for 181 countries, 1980-2008: a systematic analysis of progress towards millennium development goal 5. Lancet 2010; 375:1609-23

4. Wei SQ, Qi HP, Luo ZC. Maternal vitamin D status and adverse pregnancy outcomes: a systematic review and metaanalysis. J Matern Fetal Neonatal Med 2013; 26:889-99.

5. Mulligan ML, Felton SK, Riek AE. Implications of vitamin $\mathrm{D}$ deficiency in pregnancy and lactation. American J Obstet Gynecol 2010; 202:e421-9.

6. Sung CC, Liao MT, Lu KC, Wu CC. Role of vitamin D in insulin resistance. BioMed Research International. 2012 doi: 10.1155/2012/634195

7. Wortsman J, Matsuoka LY, Chen TC, Lu Z, Holick MF. Decreased bioavailability of vitamin D in obesity. The American journal of clinical nutrition. 2000;72(3):690-3.

8. Villamor E, Cnattingius S. Interpregnancy weight change and risk of adverse pregnancy outcomes: a population-based study. The Lancet. 2006;368(9542):1164-70.

9. Sebire NJ, Jolly M, Harris JP, Wadsworth J, Joffe M, Beard RW, Regan L, Robinson S. Maternal obesity and pregnancy outcome: a study of 287213 pregnancies in London. International journal of obesity. 2001;25(8):1175.

10. Parikh SJ, Edelman M, Uwaifo GI, Freedman RJ, SemegaJanneh M, Reynolds J, Yanovski JA. The relationship between obesity and serum 1,25-dihydroxy vitamin D concentrations in healthy adults. The Journal of Clinical Endocrinology \& Metabolism. 2004;89(3):1196-9.

11. Holick MF. Vitamin D: importance in the prevention of cancers, type 1 diabetes, heart disease, and osteoporosis. The American journal of clinical nutrition. 2004 ;79(3):362-71.

12. Wortsman J, Matsuoka LY, Chen TC, Lu Z, Holick MF. Decreased bioavailability of vitamin D in obesity. The American journal of clinical nutrition. 2000 ;72(3):690-3.

13. Cnattingius S, Villamor E, Lagerros YT, Wikström AK, Granath F. High birth weight and obesity - a vicious circle across generations. International journal of obesity. 2012;36(10): 1320.

14. Morley R, Carlin JB, Pasco JA, Wark JD. Maternal 25hydroxyvitamin $\mathrm{D}$ and parathyroid hormone concentrations and offspring birth size. The Journal of Clinical Endocrinology \& Metabolism. 2006 ;91(3):906-12.

15. Kim SY, Dietz PM, England L, Morrow B, Callaghan WM. Trends in pre-pregnancy obesity in nine states, 1993-2003. Obesity. 2007;15(4):986-93.

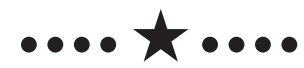

